\title{
Describable Class
}

National Cancer Institute

\section{Source}

National Cancer Institute. Describable Class. NCI Thesaurus. Code C43443.

Abstract class that allows subclasses to inherit the association to Description, for detailed annotations such as Ontology entries and Database references, the association to Audit, for tracking changes, and the association to Security for indicating permissions.

(caMAGE) 